\title{
VENEZUELA Y LA CRISIS MÁS FUERTE EN LA HISTORIA DE AMÉRICA LATINA
}

\section{Venezuela e a crise mais forte da história da América Latina}

\author{
Manuel Sutherland \\ Universidad Central de Venezuela (CENDES) \\ Ciudad Universitaria de Caracas, Venezuela.
}

\section{Informações do artigo \\ Recebido em 21/06/2020 Aceito em 25/10/2020}

doi>: https://doi.org/10.25247/2447-861X.2020.n250.p279-304

Esta obra está licenciada com uma Licença Creative Commons Atribuição 4.0 Internacional.

\section{Como ser citado (modelo ABNT)}

SUTHERLAND, Manuel. Venezuela y la crisis más fuerte en la historia de América Latina. Cadernos do CEAS: Revista Crítica de Humanidades. Salvador/Recife, v. 45, n. 250, p. 279-304, maio/ago. 2020. DOI: https://doi.org/10.25247/2447861X.2020.n250.p279-304

\begin{abstract}
Resumen
Es extremadamente difícil en un breve artículo elaborado para una revista extranjera, explicar la magnitud de la crisis venezolana y, sobre todo, explayarse en la multiplicidad de factores que la llevaron hasta ese extremo nada deseable. Por ende, en este trabajo se reflexiona críticamente sobre los factores más importantes de la debacle, con la lamentable exclusión de muchos elementos interesantes para el análisis. A junio de 2020 el problema con la censura de datos continúa. También hay muchas estadísticas que no se han actualizado desde hace mucho tiempo, lo cual dificulta en extremo el análisis. La crisis política desatada en enero de 2019 con la auto proclamación, como Presidente de la República, del Presidente de la Asamblea Nacional Juan Guaidó, trajo consigo una serie de eventos extremadamente importantes. Ellos van desde intentos de insurrecciones militares hasta el reforzamiento de sanciones, confiscación de bienes nacionales en el extranjero y la reciente incursión guerrillera en mayo de 2020. Una generalización de los temas más llamativos, de carácter político, se puede leer en el texto, haciendo énfasis en el análisis de las acciones de la oposición más beligerante y en el devenir del diálogo entre las partes en conflicto.
\end{abstract}

Palabras Clave: Crisis. Corrupción. Rentismo. Insurrecciones. Diálogo.

\section{Resumo}

É extremamente difícil, em um pequeno artigo preparado para uma revista estrangeira, explicar a magnitude da crise venezuelana e, acima de tudo, elaborar a multiplicidade de fatores que a levaram a esse extremo indesejável. Portanto, este trabalho reflete criticamente os fatores mais importantes do desastre, com a infeliz exclusão de muitos elementos interessantes na análise. Em junho de 2020, o problema com a censura de dados continua. Também existem muitas estatísticas que não são atualizadas há muito tempo, tornando a análise extremamente difícil. A crise política desencadeou em janeiro de 2019 com a autoproclamação, como Presidente da República, do Presidente da Assembléia Nacional Juan Guaidó, trouxe consigo uma série de eventos extremamente importantes. Eles variam de tentativas de insurreições militares até sanções mais rigorosas, confisco de ativos nacionais no exterior e a recente incursão de guerrilha em maio de 2020. Este último tópico foi trabalhado em formato curto em um artigo específico: (Sutherland, como foi o Paródia venezuelana da Baía dos Porcos, 2020). Uma generalização das questões mais marcantes, de natureza política, pode ser lida no texto, enfatizando a análise das ações da oposição mais beligerante e a evolução do diálogo entre as partes em conflito.

Palavras-chave: Crise. Corrupção. Rentismo. Insurreições. Diálogo. 


\section{Apuntes muy breves sobre el surgimiento del chavismo como corriente política}

En 1998 el Chavismo surgió como alternativa política con base a un discurso nacionalista que retrotrae al imaginario de la "Gran Venezuela". Con una retórica popular y patriótica, el proyecto bolivariano se vendía como una esperanza de regreso a los años de esplendor de la economía. Parecía que el único problema era la distribución corrupta y clientelar de la renta petrolera. Lo único que había que hacer era "adecentar" y volver presentable a la clase política, estimular a los industriales nacionalistas y poner en cintura a las rapaces transnacionales. Sin prácticamente mencionar a la clase obrera y a las necesidades de desarrollo de las fuerzas productivas, el proyecto bolivariano expresó el descontento general que estaba harto de los paquetes de ajuste macroeconómicos del FMI, la austeridad, las devaluaciones y la merma del poder adquisitivo (RONDÓN, 1998).

Aunque en toda campaña política las promesas electorales son tan fastuosas y resistentes como pompas de jabón, entre todos los candidatos a la elección presidencial de 1998 la frase "diversificación de la economía y desarrollo industrial" estuvo de moda. Sin embargo, en el proyecto político ganador no hubo propuestas firmes de desarrollo industrial, planteadas en algún programa de desarrollo específico, más allá de los consuetudinarios: planes de gobierno que todos olvidan al ganar. La idea era tomar el poder y empezar a distribuir la renta que emanaba de la gran abundancia petrolera. El país es rico, pero los pobres no pueden acceder a esa riqueza, por la nefasta interdicción de las élites dominantes (la oligarquía) cuya avaricia a toda prueba había hundido las posibilidades de un desarrollo armónico. El problema en ese entonces no era el capitalismo, era simplemente la vil codicia de la plutocracia que había puesto un dique de contención entre la riqueza y el muy "homogéneo" pueblo pobre.

El chavismo como movimiento era puramente nacionalista, popular, bolivariano y densamente militar. Su líder, el Teniente Coronel Hugo Chávez, amaba a las Fuerzas Armadas y a toda la simbología patriótica que emanaba. Con apasionado ahínco hablaba del amor a su tierra, a la patria. En 1998 el socialismo jamás aparecía en su horizonte electoral y la mayoría de compañeros de relevancia de su fórmula, insertos en el Movimiento Quinta República, eran de extracción militar. Siendo ellos del ámbito castrense, siempre demostraban sus posturas religiosas profundas y su poca empatía con las causas propias de las luchas identitarias modernas: género, sexo diversidad, raciales, derechos humanos, legalización de 
drogas blandas, ecología etc. Dichas luchas les eran por completo indiferentes, en el mejor de los casos.

Las Fuerzas Armadas venezolanas de esa época habían sido tuteladas por casi dos mil oficiales del US Army, quienes vivían y trabajaban en las inmediaciones del fuerte militar más importante de la nación: Fuerte Tiuna. La misión militar permanente multitudinaria se nutría de masivas visitas y ejercicios conjuntos de cooperación. Las Fuerzas Armadas recibían religiosamente las clases de estos profesores y la educación de un ejército completamente anticomunista. El aparato castrense tenía el privilegio de haber aplastado con rigurosidad, y sólida suficiencia, a todos los intentos de lucha armada izquierdista, de guerrilla urbana y de insurrecciones populares. A diferencia de lo que había sucedido (o sucede, como en Colombia) en latitudes cercanas, las Fuerzas Armadas tenían un gran prestigio como ente de control social y se habían mantenido fuera de la acción política por mucho tiempo, exceptuando los golpes de Estado (4 de febrero de 1992 y 27 de noviembre de 1992) protagonizados por facciones minoritarias de las mismas, que dirigían precisamente los militares que ahora querían acceder al poder por la vía electoral.

Muchos de los militares inmersos en la campaña electoral con Chávez, fueron alumnos de la sanguinolenta Escuelas de las Américas, infelizmente conocida por ser la academia de famosos militares violadores de derechos humanos y furibundos dictadores anticomunistas. A pesar del masivo apoyo de la microscópica izquierda tradicional al proyecto chavista, el componente militar era indiscutiblemente hegemónico, aunque astutamente velado. Esto sería clave para el sostenimiento del poder a pesar de todas las crisis y sería factor esencial para entender que el supuesto "viraje" hacia el socialismo del siglo XXI, seis años después de acceder al poder, no era más que guiño ideológico fuertemente mediatizado, en virtud de ofrecer una base teórica que de alguna manera diera sustento formal al proyecto. Poco más.

\section{Los primeros años de gobierno, en síntesis...}

Años después del triunfo electoral del 6 de diciembre de 1998, incrustados en diversos planes de gobierno y en algunos discursos, el Presidente Chávez trató de alguna manera de tocar el tema del desarrollo de las fuerzas productivas. Aunque el énfasis parecía más bien orientado hacia el rescate de la renta petrolera, es decir, arrebatarle a la "tecnocracia 
meritocrática" de PDVSA y a las "transnacionales" el ingreso rentístico que, según el Presidente decía, le pertenecía al pueblo y que debía ser administrado y distribuido por un gobierno popular. Acá no hay ningún cuestionamiento en lo relativo a los gravísimos efectos que trae consigo lo que en las ciencias sociales modernas venezolanas, se conoce como Capitalismo Rentístico, tema brillantemente trabajado por Asdrúbal Baptista y Bernard Mommer. La mar de enseñanzas prácticas de los auges rentísticos petroleros, producto de crecimientos fulgurantes en el precio del petróleo, fueron olímpicamente ignorados. La propia disposición estructural del capitalismo en Venezuela no fue cuestionada en lo absoluto, lo grave era que PDVSA no ofrecía suficiente renta al fisco y que había luego que distribuirla a los más pobres de manera más rápida y extensiva.

Los primeros años del gobierno bolivariano (1999-2001) fueron años de un gobierno bastante conservador. No hubo cambios estructurales y la dinámica rentística no se observaba. Fueron años de "vacas flacas", precios del petróleo que rondaron, sobre todo al inicio, los 12 \$ por barril. El país seguía una inercia de crecimiento moderado y hacia finales del período comentado, se vio beneficiado por un auge en el precio del petróleo y una expansión de la producción de hidrocarburos interna. Todo ello fomentó un crecer substancial de los salarios que llegaron, como sueldo mínimo, a alcanzar en 2001 los 400 dólares ${ }^{1}$, lo que aunado a los enormes subsidios en los servicios públicos, daba la sensación de una especial holgura económica y colocaba a la clase obrera venezolana como la mejor pagada de América Latina.

Hacia finales del año 2001 el gobierno en ciernes planteó una serie de leyes que pretendían imponer una serie de cambios llamativos en la economía (GARCÍA BRITO, 2004). Las 49 leyes que se presentaron planteaban reformas que por lo general pretendían apoyar a pequeños productores; leyes que en la mayoría de los casos eran de índole moderada. Dicho bloque de propuestas causó el primer gran impasse con la gran burguesía nacional. La aceptación de esas leyes en noviembre de 2001 causó un revuelo empresarial sin precedentes. La más odiada de esas leyes fue la llamada Ley de Tierras y Desarrollo Agrario. Esta ley fue impulsada por la "Coordinadora Agraria Nacional Ezequiel Zamora" (CANEZ), 
compuesta por alrededor de 4600 organizaciones de base de las diferentes regiones del país (GARCÍA BRITO, 2004). La ley decía, grosso modo, que la totalidad de tierras estatales pasaban a ser propiedad social, para con ello emprender un proceso de parcelización masivo de esas tierras, en favor de los campesinos sin propiedad. La ley preveía la afectación de tierras consideradas como "latifundios"; que según esa norma, eran las propiedades que tuvieran más de 5000 hectáreas en condición de ociosas.

\section{La feroz y desproporcionada reacción de las élites conservadoras venezolanas}

La implantación de la ley de tierras trajo cola. Una feroz y desatinada reacción de la burguesía agraria y del empresariado en general derivó en un proceso que abrió las puertas a la masificación de la práctica del sicariato campesino, antes desconocida en el país. En pocos años asesinaron a más de noventa líderes campesinos que exigían tierras (GARCÍA BRITO, 2004). Como era de esperarse, hasta una década después, ningún terrateniente ha sido juzgado por ningún crimen, lo que ha dado un manto de impunidad tremendo. Así las cosas, en diciembre de 2001 se realizó un gigantesco lockout patronal. De manera extensiva cerraron la mar de empresas en todo el territorio nacional por varios días. Se empezó a hablar de dictadura castrocomunista por la íntima relación política de Chávez y Fidel Castro, que se materializaba en diversos intercambios institucionales, motivados por el intento bolivariano de bypassear al Estado heredado de la llamada Cuarta República. El paro fue un gran éxito y a partir de ahí se desató una feroz ofensiva por defenestrar a un gobierno que apenas daba sus primeros pasos.

A pesar del gran apoyo popular que el gobierno tenía, las élites emprendieron una campaña de gran calado para desprestigiar y tachar de comunista a un gobierno que siempre se desmarcaba taxativamente del término. Los meses de enero a abril de 2002 fueron un polvorín in crescendo. Día a día se agitaban los ánimos para decir que el país se acercaba al abismo, que íbamos para una situación caótica, aunque los números macroeconómicos del año 2001 fueran muy buenos: crecimiento económico, altos salarios, baja inflación (para lo que era el nivel inflacionario inercial en Venezuela) y estabilidad cambiaria. A pesar de todo ello, la gran burguesía emprendió el anti democrático y estéril camino de la confrontación y el golpe de Estado. 
En abril de 2002 se intensificó un paro patronal reforzado con una serie de infinitas marchas (multitudinarias) que fueron colapsando al país y causando daños irreparables. La extracción de petróleo disminuyó casi a cero barriles. Miles de trabajadores de la estatal PDVSA eran furibundamente anti chavistas, devengaban sueldos muy elevados y muchos habían trabajado para transnacionales o estudiado con becas en prestigiosas universidades extranjeras. Veían en el chavismo poco menos que el anatema de la intervención política a su empresa. Por ende, con vigoroso entusiasmo se adhirieron al parón de actividades que solamente exigía la renuncia irrevocable del Presidente Chávez y todo lo que a chavismo se pareciese.

El 11 de abril de 2002 amanecía con la música de marchas y contramarchas. De un lado a otro de la capital, los sectores chavistas y anti chavistas se concentraban ardorosamente. Como ejércitos se preparaban, sin saberlo sus bases, para una más que probable conflagración. Esa tarde la marcha opositora emprendió un camino directo hacia el palacio de Miraflores, para derrocar al Presidente en ejercicio. La inevitable confrontación estalló, decenas de muertes se sucedían y el alzamiento militar tuvo su apogeo. A la noche de esa infausta fecha para la democracia nacional, el Presidente Chávez fue depuesto y encarcelado. Al día siguiente unos pocos comercios abrieron y el muy famoso ancla de TV, Napoleón Bravo, comentó: Venezuela... tenemos nuevo Presidente.

El golpe de Estado fue exitoso, al serlo, muchas personalidades que hoy en día se hacen llamar "demócratas", salieron a apoyarlo en entrevistas televisadas que quedarán para la historia. En ese interinato de 36 horas, el Presidente de la cámara de empresarios más importante del país (FEDECAMARAS), el inefable Pedro Carmona Estanga, pasó por Miraflores y asumió la Presidencia de la República, así, sin más. En 20 minutos derogó con un súper decreto todo lo que había hecho el chavismo a través de leyes y elecciones; y desató una pertinaz cacería de brujas contra todo color rojo. Se apresaron, golpearon y hostigaron a personajes chavistas de toda índole. Los que supuestamente se refugiaban en embajadas, fueron brutalmente asediados y frontalmente amenazados de linchamiento. La pesadilla golpista acababa en pocas horas con enormes pérdidas para la nación que se veían reflejadas en una caída de casi el $10 \%$ del PIB, ya que meses después, en diciembre de 2002 , se realizó otro paro patronal que se extendió por meses, quizás hasta marzo de 2003. La virulenta vendetta antichavista de la época expresa el terror que siente el chavismo de abandonar el 
poder que detenta aún en 2020, el miedo a una razzia sanguinolenta los aferra firmemente al poder aún cuando el país sufra la peor crisis de su historia. Esas heridas aún no han sido cerradas.

\section{La superación de los feroces embates del antichavismo anti socialista}

Con el pasar de los años y habiendo superado el "paro petrolero" y el "golpe petrolero" (2002-2003), el régimen político fue creciendo en ambiciones ideológicas y del llano nacionalismo mutó hacia el ideario del "socialismo del siglo XXI". Dicho momento quedó inmortalizado en el discurso del Presidente Chávez en el Foro Mundial de Porto Alegre en aquel lejano 30 de enero de 2005 (GARRIDO, 2005). Seis años después de su primer año de mandato, el gobierno cambiaba de norte ideológico. Este socialismo del siglo XXI se iba a diferenciar largamente del socialismo de estilo soviético e iba a buscar un equilibrio entre lo mejor de dos mundos. Aunque algunos de sus más avezados fanáticos hicieron congresos y seminarios para definir qué es el socialismo del siglo XXI, el gobierno (astutamente) jamás lo hizo. De manera un tanto "picaresca", el gobierno dejó como en una página en blanco la conceptualización de la nueva ideología adoptada. De tal forma que en el socialismo del siglo XXI entraran todos: la izquierda internacional radical y moderada, las Fuerzas Armadas como hegemón, las bases populares y la mar de políticos tradicionalmente derechistas que habían visto en el chavismo una fácil oportunidad de hacerse de un control político con escaso esfuerzo y talento. Obviamente, el último decisor era simplemente el caudillo iluminado, el pastor de pueblos, el gran árbitro entre las propuestas de todos: el comandante presidente.

Con una renta petrolera en manos del poder Ejecutivo y con un apoyo masivo que le permitió al chavismo triunfar con un margen histórico en las elecciones presidenciales del año 2006, se empieza a consolidar un incremento sideral en los ingresos por exportaciones y comienza la etapa en la cual muchos pensaban, iba a desarrollarse al fin el proyecto de industrialización nacionalista que "sembraría" el petróleo en una serie de máquinas e instalaciones que podrían servir para sustituir importaciones de bienes manufacturados en el mediano plazo.

Los constantes llamados de Chávez a estudiar marxismo, enarbolados después del 2006, levantaron un gran entusiasmo entre muchos obreros industriales, ya que se sintió que 
había una oportunidad histórica de emprender un proceso socialista de industrialización nacional, que tuviera tras de sí una enorme renta petrolera de respaldo. Como el proceso bolivariano se llama a sí mismo revolucionario y socialista, era de esperar que de alguna manera siguiera las incansables palabras de Marx en relación a la necesidad de desarrollar con la mayor ciencia, tecnología y planificación, los procesos industriales, en síntesis: desarrollar fuerzas productivas. Más aún, con las experiencias de desarrollo industrial en la URSS, China y la RDA, se creía que la clase obrera podría llegar a ser el verdadero sujeto histórico del cambio social; sujeto que habida cuenta era nada más y nada menos que el militar. La propuesta industrializadora parecía indetenible, ya que aparte de manejar el Estado casi por completo en franca concentración absoluta de poderes, se poseía una renta del suelo minera tan generosa que haría el camino más breve. A pesar de todo lo anterior, nada fue como se imaginó.

\section{El ciclo económico determinado por la ciclicidad del precio de las materias primas}

El ciclo económico en Venezuela se puede observar en su manifestación más sencilla: en las variaciones interanuales de su Producto Interno Bruto (PIB). En la figura 1 se puede observar una fuerte desemejanza en el ritmo de crecimiento de la economía. Enérgicos ciclos de auge y caída determinan la movilidad extrema de la producción, que refleja la feroz volatilidad en los precios del petróleo. El preciado hidrocarburo constituye el $95 \%$ de las exportaciones en los años de auge en los precios (2012) y cerca del $65 \%$ en los años donde el precio del petróleo es considerado bajo (1998) (BCV, 2014), es decir, cuando la renta es exigua y el negocio petrolero ofrece una ganancia similar a la de una producción industrial normal. 
Figura 1 - Evolución del PIB en Venezuela (1950-2018)

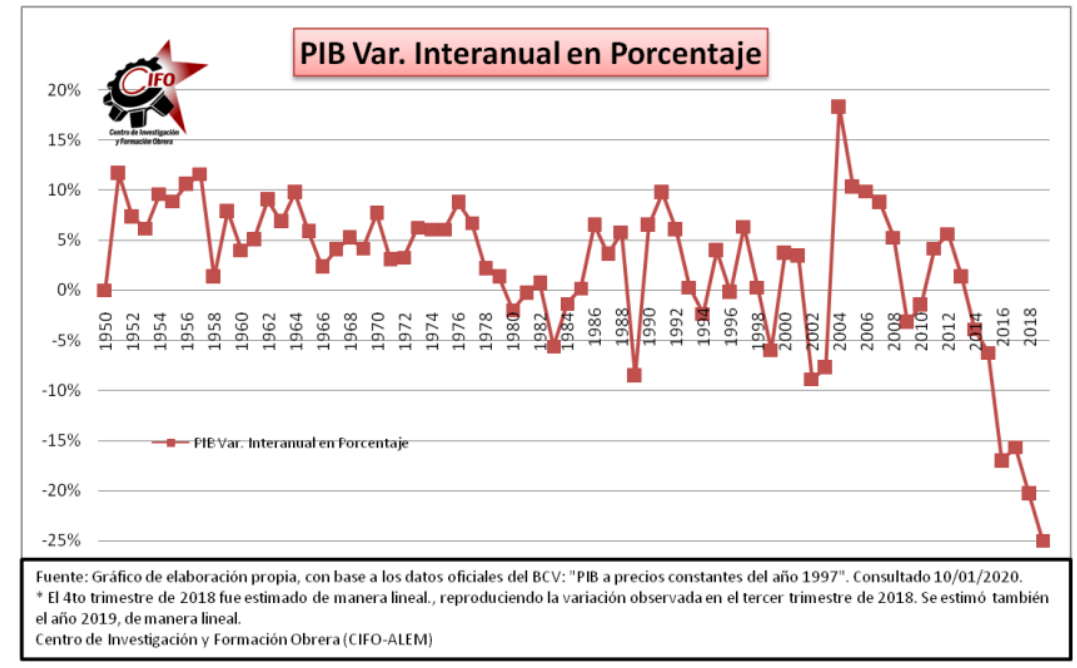

Fuente: Gráfico de elaboración propia con los datos de: (BCV, Banco central de Venezuela, s.f.)

En la figura 1 también se denota que los ciclos recesivos en la economía empezaron a sucederse a partir de la década de 1980, donde parece que la "edad de oro" económica de Venezuela ha llegado a su fin. Los primeros años de ésa década mostraron la vigorosa influencia de la llamada "crisis de la deuda" que ahogó a muchos países y que se manifestó con una profunda caída en los índices de precios de los commodities, ello redujo los ingresos por exportaciones y los hizo entrar en default a muchos de ellos.

En el período bolivariano que se muestra en la figura 1 (1999-2018), se ve que en su primer año hubo una fuerte caída atribuida al bajo precio que reflejaba el petróleo (alrededor de 9 dólares el barril) y quizás a una probable incertidumbre gracias al advenimiento de un gobierno nuevo que prometía grandes cambios. Posteriormente (2002) se refleja una súbita caída del PIB en el cual los bajos precios del petróleo se entretejen con el golpe de Estado, que derrocó por 36 horas al entonces Presidente Hugo Chávez (11 de abril de 2002). El oficialmente llamado coup d'etat fue acompañado por un macizo paro patronal que siguió casi todo el empresariado local. El 2003 empezó con el mismo lockout patronal que se extendió hasta marzo, como ya antes explicamos. Lo excepcionalmente bajo del PIB del año 2003 y por ende de la caída en la producción industrial y la productividad del trabajo industrial de esa fecha, que se observará en todas las gráficas, obedece más a factores extraeconómicos (diríase políticos) que a situaciones de índole económica o fabril. Lo anterior contrasta con el 
enorme salto en el crecimiento del año 2004 (18\%), que parece más un rebote de la economía, que otra cosa.

Siguiendo en la figura 1, se revela que la economía en la época (2005-2008) creció a tasas elevadísimas (alrededor de $8 \%$ interanual), impulsadas por un fabuloso auge en la renta petrolera que multiplicó el ingreso por exportaciones en más de tres veces. La "edad de oro" del gobierno actual es donde el movimiento político bolivariano se muestra más agresivo, empieza a hablar del "socialismo del siglo XXI" (año 2005), comienza con planes de integración comercial (ALBA en vez del ALCA) y emprende un proceso de estatizaciones de algunas grandes empresas industriales y de servicios, tales como cemento, acero, telecomunicaciones, banca y minería (SUTHERLAND, 2016). La abrupta caída de los precios del petróleo a finales de 2008 y a lo largo del 2009, que reflejaron los embates de la crisis mundial de 2007-2008, frenaron en seco enormes proyectos de inversión y ambiciones políticas más elevadas. En 2011 se observa una formidable recuperación de la senda de crecimiento económico derivada de un nuevo incremento en los precios del petróleo, que pasan de estar en 35 \$ por barril (2009) a elevarse hasta rozar los 120 \$ en la época que comprende los años 2011-2013. Obviamente, todo lo anteriormente narrado afecta al devenir de la productividad del trabajo industrial, por la más que comprobada relación entre la variación de los ingresos petroleros y la producción industrial (MOMMER, 2003, 1998).

En los años de 2014 y 2015 el precio del petróleo empieza a caer. Aunque triplica y en algunos períodos quintuplica a los precios que se tenían en el año 2001-2002, el ritmo incrementado de gastos del gobierno y la hipertrofia en las importaciones hacen que precios del petróleo mucho más altos que los observados a inicios del década del 2000 (BCV, 2016), luzcan "pequeños" ahora. En esos últimos años empieza la contracción de las importaciones, la caída en la oferta de bienes y servicios, y empiezan a reflejarse los resultados de un proceso de desindustrialización, tema central que nos atañe, que en favor de un fervor importador llega a traer leche líquida, cemento, gasolina, plástico y obreros (chinos) para construir viviendas.

La caída voraz en la producción y en la productividad hizo más patente la escasez de bienes, con lo cual se agudizó el incremento en el precio de los mismos. La enorme impresión de dinero inorgánico, componente útil para la expansión del gasto y la cobertura de déficit fiscales, se vio reflejada en un aumento de la base monetaria en más de 125 mil \% (de enero 
1999 a enero 2017) (SUTHERLAND, 2017). Todo ello incrementó las tasas de inflación (2015) a casi el doble de la inflación más alta de nuestra historia (1996). En ese panorama se circunscribe la vertiginosa caída en el PIB del año 2015, como un posible reflejo de un agotamiento en el proceso nacional de acumulación de capital, que tiene como eje central a la apropiación de la renta de la tierra petrolera. Apenas acaeció un descenso de la renta, se pareció inhibir la producción agrícola e industrial y empezó a disminuir fuertemente el salario.

La justificación del incremento en la importación no se elaboró jamás, hubo poca crítica social en ese festín. Por una parte la sobrevaluación gigantesca del tipo de cambio hacía que todo lo importado fuese más barato que lo nacional. Por otra parte, la importación bajo un férreo control de cambio de divisas entregadas discrecionalmente abría unas posibilidades infinitas de corrupción que hicieron a muchos multimillonarios. El control político que otorga la asignación discrecional de divisas increíblemente baratas le dio al gobierno la posibilidad de cooptar y presionar al empresariado y domesticar a los partidos políticos que de la patronal dependían. A la gente común le vendían divisas para turismo a precios muy por debajo del dólar de mercado, por ende, viajaron, gastaron, hicieron fraudes cambiaros y todos felices. Fue un negocio redondo.

Una de las formas más simples de ver el avance de un proceso nacional de acumulación de capital, es estudiar las variaciones del PIB per cápita. De manera sencilla se puede observar la evolución del ingreso en una economía, sin reparar en la distribución del mismo. Aunque el PIB en su comportamiento muestre la normal ciclicidad de toda economía capitalista, el PIB per cápita muestra más bien las tendencias de la acumulación puestas en relación con el crecimiento poblacional, que en Venezuela ha sido bastante alto. En la figura 2 se muestra, desde 1951 hasta nuestro tiempo, la evolución del PIB per cápita, que inmediatamente al llegar el gobierno bolivariano detenta un ligero repunte, para luego desplomarse en 2003 por las razones ya expuestas. El posterior control de la situación política se entroncó con un inusitado auge de la renta a mediados del año 2004. Los precios se elevaron exponencialmente y pasaron de un tímido \$ 10 por barril a estabilizarse en torno a los \$100. De un PIB per cápita cercano a Bs. 1.400.000 (poder adquisitivo de 1997), se salta a un PIB que casi roza los bs. 2.100.000 (BCV, 2016). El crecimiento fue tan fuerte que casi alcanza al pico histórico obtenido en 1977. 
Figura 2 - Gráfico del PIB per cápita (1951-2018)

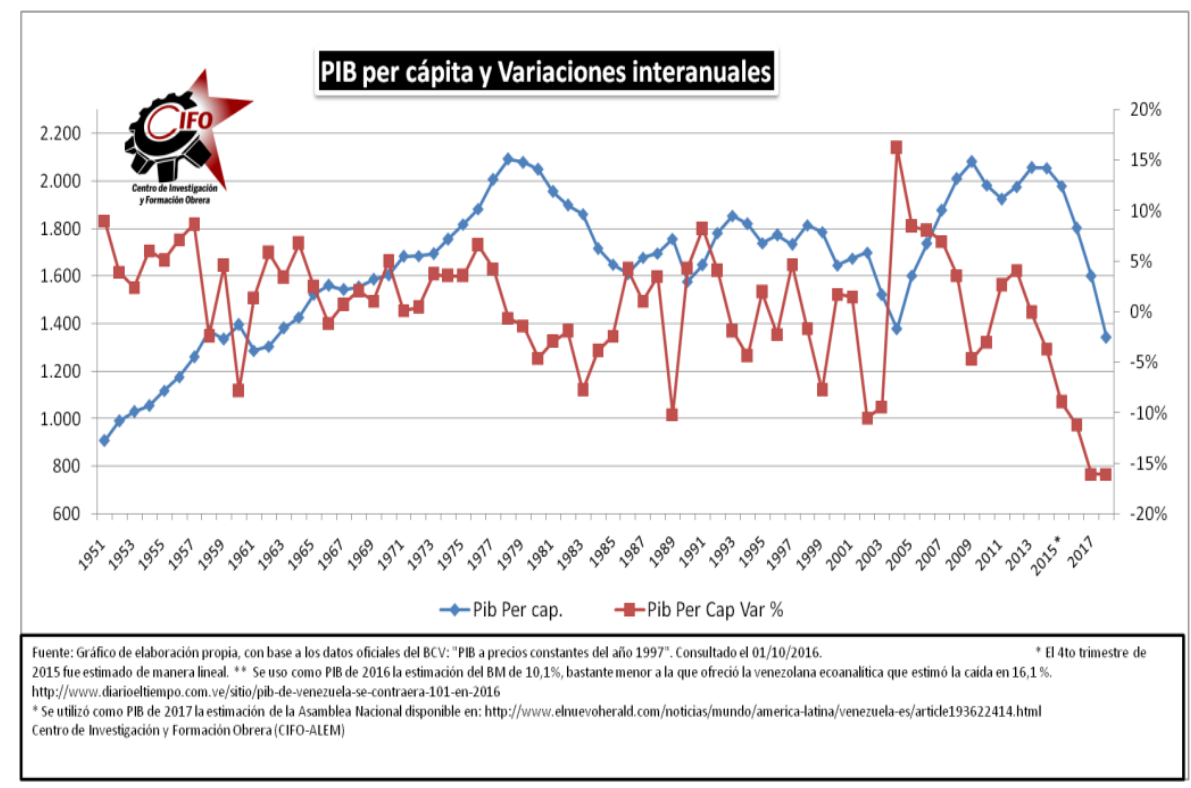

Fuente: Gráfico de elaboración propia con los datos de BCV. PIB a precios constantes del año 1997. El 4to trimestre de 2015 fue estimado de manera lineal. Para el año 2016 se estimó una caída del $7 \%$ en el PIB. Para 2017 y 2018 se estimaron caídas del $16 \%$, considerablemente más bajas que las estimaciones del FMl y de la AN

La expansión duró un tiempo excepcionalmente largo y en ella se profundizaron los males que traen aparejados los estallidos repentinos en el ingreso petrolero. La industria y el agro fueron reducidos con la hoz de un tipo de cambio muy sobrevaluado (la sobrevaluación superó el $10.000 \%$ en el 2015) (KORNBLIHTT, 2015). Lo importado fue extremadamente barato y se desincentivó cualquier esfuerzo productivo industrial. Estado y empresarios se volcaron a la tarea de exportar la renta petrolera a base de importaciones recrecidas, la fuga de capitales se disparó y se desarrolló un endeudamiento externo a onerosas tasas de interés (KORNBLIHTT, 2016).

\section{El fin del súper ciclo de materias primas y el rentismo ahogado en su propio devenir}

El final del ciclo de expansión rentístico se evidencia en el período 2014-2018, un quinquenio que se caracterizó por cinco caídas sucesivas en el PIB per cápita, algo nunca antes visto en nuestra economía. Para los años 2017 y 2018, se vio el agravamiento de la crisis con el penoso protagonismo de una híperinflación que ha roto casi todos los récords históricos para América.

De forma extremadamente sintética se diría que la situación actual se presenta: 
a) Por quinto año consecutivo el país exhibió la inflación más alta del mundo estimada según la Asamblea Nacional (AN) en 1.698.488,2 \% para el año 2018 (CALLAMA, 2019). Aunque considero que la estimación de la AN es exagerada, la estimación oficial de la inflación que ofrece el BCV, de 130.060,01\%, parece quedarse corta, debido a que la metodología empleada subestima los precios de muchos bienes al tomar sólo las versiones "reguladas" por el gobierno nacional. En los meses del tercer trimestre de 2019 se ha notado una gran desaceleración de la inflación en Venezuela. La inflación acumulada entre enero y octubre de 2019 alcanza el 3.000\%, lo que sería alrededor del 3\% de la inflación acumulada para el mismo período del año pasado, eso no quiere decir que no sea extremadamente alta y destructiva.

b) Según la Comisión de Finanzas de la $\mathrm{AN}$, la economía se ha contraído en un impresionante 50,61 \% en el breve período que va desde el 2013 al 2018, una destrucción económica nunca antes vista en América (EL NACIONAL, 2018). La estimación oficial del BCV no se queda muy lejos de esa cifra y ubica la contracción en un impresionante $47,7 \%$.

c) El colapso es innegable. El primer trimestre de 2019 el PIB cayó, según el BCV, en un $24 \%$ con respecto al trimestre pasado, fue quizás el peor trimestre en la historia económica de la nación. A la inercia natural de la destrucción económica que se arrastra desde 2014, se le unió una crisis política profunda (con la auto proclamación de Juan Guaidó como Presidente "encargado" de la República) y un caos en el servicio eléctrico, de proporciones ante diluvianas, que sumergió al país en la total oscuridad por muchos días, tema importante que más adelante abordaremos. Ese nefando cóctel derivó en ese descenso de casi un cuarto de la economía, en apenas un trimestre.

d) Venezuela posee además un déficit fiscal de dos dígitos (al menos por sexto año consecutivo), el riesgo país más alto del mundo (más de 6000 PB en el EMBI+ de JP Morgan), las reservas internacionales más bajas de los últimos 20 años (menos de 8.000 millones de US\$) y una fuerte escasez de bienes y servicios esenciales (alimentos y medicinas), que se ha visto parcialmente paleada con un aluvión de 
importación de mercadería que es vendida en dólares, con elevados precios dada la baja escala del negocio. Con estos datos, más las sanciones financieras de EEUU-UE, es imposible solicitar financiamiento externo en los mercados tradicionales.

e) El valor del dólar paralelo (que sirve para fijar casi todos los precios de la economía) se incrementó en más de $88.000 \%$ a lo largo del año 2018, lo cual ha desintegrado por completo el poder adquisitivo (BCV, s.f.). Ello ha sido impulsado por un vertiginoso incremento de la liquidez monetaria en un 68.000\% (2018). Para el 2019 la ampliación de la liquidez monetaria ha sido mucho menor, $2.600 \%$ hasta octubre, pero insólitamente elevada para las necesidades de estabilidad económica requerida.

f) El salario real para el período 2013-2018 descendió en 95\%. Aunque en octubre de 2019 el salario más el bono de alimentación se han elevado a un equivalente de 9 dólares mensuales, medidos al tipo de cambio "oficial" que luego de la eliminación de facto del control cambiario expresa una cotización muy similar al precio que ofrece el paralelo ${ }^{2}$, ello no deja de ser un ingreso extremadamente precario, por más que muchos servicios públicos tengan precios diminutos, como por ejemplo gasolina, agua y luz eléctrica.

\section{¿Una dolarización «antiimperialista» y revolucionaria?}

La economía venezolana se "dolarizó", de facto, en medio de la híperinflación y la drástica reducción de la base monetaria. ¿Cómo el dólar pasó de ser la causa de todos los males a una suerte de «bendición» para el gobierno de Nicolás Maduro, que hizo «aparecer» nuevamente buena parte de los bienes con un fuerte costo en términos de desigualdad?

\footnotetext{
2 Después de eliminar el control de cambios, derogar la ley de ilícitos cambiarios y permitir la comercialización plena con divisas (marzo de 2019), se habla del tipo de cambio "paralelo" al que ofrecen informales páginas Web que monitorean las cotizaciones diarias. El tipo de cambio "oficial" es el referido al cotizador que indica el índice de los intercambios de divisas en las mesas de dinero interbancarias, donde el protagonismo lo tienen las acciones acometidas por la banca privada. Ello hace que ese tipo de cambio "oficial" porque es publicado por el BCV, sea muy similar al tipo de cambio paralelo.
} 
El gobierno bolivariano se ha caracterizado por un inusualmente encendido verbo «anti yankee». En los últimos años los vituperios contra todo lo que representa Estados Unidos han sido más que recurrentes debido al franco apoyo de Donald Trump a la oposición más beligerante. Por todo ello y por las espinosas sanciones económicas impuestas desde Washington ha sido muy fácil elevar permanentemente acusaciones de «sabotaje» y de «guerra económica». Para los seguidores más entusiastas del gobierno, el dólar estadounidense representa así el cúmulo de todos los males económicos de una nación sacudida por el colapso macroeconómico más profundo de su historia y la número nueve en el mundo (en los últimos 70 años).

Para los "guerreros económicos"3 de Nicolás Maduro, todos los males se achacan a la nefanda influencia del dólar en la economía venezolana, que de manera consuetudinaria ataca a la moneda nacional hasta despreciarla por completo. Esta pérdida de valor del bolívar sería la culpable de la híperinflación, la baja de salarios y la crisis en general. Así las cosas, en el 2018 aseguraban que el aumento en $42.000 \%$ en la base monetaria, exclusivamente emitida por el Banco Central de Venezuela, no tenía nada que ver con la híperinflación, es decir, no importa cuánto dinero se lance a la calle, su influencia en los niveles de precios sería cero.

De tal forma, se vendió la tesis que el dólar es la punta de lanza del ataque imperial contra la patria, y que el gobierno haya aumentado, en los dos últimos años, la base monetaria en más de $2.400 .000 \%$ sería irrelevante. Blandiendo esta tesis, parte de la

3 Se le dice: "guerreros económicos" a los economistas (y de otras profesiones) que con entusiasmo apoyan al gobierno y con fervor aplauden sus propuestas más delirantes. Vistos los espantosos resultados económicos, de lejos, los peores de gobierno alguno en el planeta, para vitorear al gobierno han debido crear una mega excusa universalizante que permita hacer creer a los incautos que el desastre económico no tiene nada que ver con la gestión del gobierno y que éste es sólo víctima de una agresión permanente que sabotea sus esfuerzos de estabilidad macroeconómica. Para hacer eso esgrimen la fementida tesis de la "guerra económica", mediante la cual van desde decir que: la inflación no existe en la vida real (Luis Salas), que la inflación es inducida por una página web (Pascualina Curcio), que la crisis económica es una inyección exógena del gobierno de EEUU (Tony Boza), que la emisión de dinero, no importa la cantidad, no incide en los niveles de precios (Juan Valdez), que los empresarios en medio de la terrible crisis actual tienen ganancias frecuentes, o incluso promedio, de mil, dos mil y diez mil por ciento (Adán González). Sobre esta flor de delirios se tejen una montaña de propuestas con unos niveles de absurdo propios de un guión de una comedia de bajo presupuesto y escaso talento. En el Centro de Investigación y Formación Obrera (CIFO) les hicimos una breve crítica: Crítica a las medidas económicas de los "guerreros económicos": Salas, Boza, Valdés, etc., que puede ubicarse fácilmente en nuestra Web (https://alemcifo.wordpress.com/2017/10/03/critica-a-las-medidaseconomicas-de-los-guerreros-economicos-salas-boza-valdes-etc/). 
izquierda internacional se ha volcado a justificar todos los problemas de la economía local, diciendo que el dólar ahoga y enajena a la población venezolana. Este es, precisamente, el caballito de batalla ideológico de los gobiernos cuya inestabilidad económica es objeto de estudio y chanza a nivel global.

\section{El Petro y la criptomoneda estatal que derrotaría al dólar antes malo y ahora "bueno"}

\footnotetext{
"En Venezuela no va a haber, ni ha habido dolarización, nuestra moneda es, y será, orgullosamente, el bolívar". (Nicolás Maduro, mayo 2015).

"La línea y el norte de Venezuela debe ser defender el bolívar como moneda soberana". (Nicolás Maduro, abr., 2018).

"Hay que evaluar como ese proceso de lo que llaman "dolarización" puede servir para la recuperación". (Nicolás Maduro, nov., 2019).
}

Hasta hace poco el mismo presidente Maduro hablaba del «narcodólar», «dólar criminal» y «dólar golpista». Con ahínco firmó decretos en favor de eliminar el dólar como moneda de cambio en el país e invirtió ingentes recursos en lanzar una criptomoneda, el petro. El petro estaría atado a las cotizaciones de varios commodities de exportación, aunque no se iba a poder «minar» como una criptomoneda normal porque estaría respaldado en las reservas de petróleo del país. La idea entonces sería que el petro fuera un medio de pago confiable y estable, aunque estuviera atado a uno de los bienes cuyo precio es muy volátil: el petróleo, cuyo valor, dicho sea de paso, disminuyó en más de un 50\% en el período 20082019. El petro, como criptomoneda estatal, es una idea llamativa pero con una pésima ejecución y diseño. Desde un principio pareció ser otro de los planes mágicos de salvación económica (como el plan de cría de "conejos urbanos"), que nos harían recuperar nuestro salario mínimo. Luego de este inusual devenir crematístico, nada nuevo ha pasado por ese derrotero.

A contrapelo de los sesudos análisis de economistas ortodoxos que aseguraban que Venezuela iba a terminar en una suerte de comunismo norcoreano, el gobierno ha experimentado desde agosto de 2018 un circunspecto, aunque vergonzante, viraje «liberal». En el marco de la segunda reconversión monetaria del chavismo, donde se le quitaron cinco ceros al bolívar (hace diez años le habían quitado tres ceros), se proyectaba el nuevo «bolívar soberano» y se prometía una ortodoxia presupuestaria severa. Déficit cero y disciplina fiscal 
emergieron de pronto en el discurso de Maduro, aunque minutos después haría exactamente lo contrario, incrementando en $3600 \%$ el Ingreso Mínimo Legal (IML), con un ensanchamiento sideral de la emisión de dinero sin respaldo. Luego de ese doloroso paso en falso que traería el inicio de la explosión de la híperinflación antes comentada, procedería a decretar la libre convertibilidad de la moneda, la importación sin mayores requisitos y la plena legalidad del comercio en divisas extranjeras. Todo ello se hizo a través de discretos anuncios en Twitter, sin la fanfarria tradicional.

Sin duda alguna hubo tres sucesos que empujaron a Maduro a esta apertura. El primero es la radical hecatombe de la economía. En sus manos, el PBI cayó un 50\% entre 2013 y 2018, y más grave aún fue la caída interanual reflejada en el primer trimestre de 2019: $-24 \%$ (BCV, s.f.). En segundo lugar está el apagón sucedido en marzo de 2019, que había dejado a millones de personas sin poder comprar, ya que el dinero en efectivo (bolívares) es extremadamente escaso, y sin electricidad era imposible comprar en comercios habilitados con puntos de venta electrónicos. Ello impulsó a los comercios a recibir casi cualquier forma de pago. En tercer lugar, el gobierno sufrió los fuertes embates de las sanciones económicas y la insurrección continua del ala más radical de la oposición. Todo ello aceleró los cambios fundamentales hacia una apertura que venía gestándose poco a poco, contradiciendo a un ala de la izquierda "progresista" que esperaba (ahora si) la «profundización de la revolución».

Lo que comenzó como una «medida de emergencia» fue mutando en una cotidianidad dolarizada que llegó al paroxismo con la declaración de Maduro en una entrevista en televisión nacional (noviembre de 2019), en donde textualmente, y sin ambages, enunció:

Yo no lo veo mal, no lo veo mal [...] Me declaro pecador. [...] Es auto regulación necesaria de una economía que se niega a rendirse. [...] Hay que evaluar como ese proceso de lo que llaman "dolarización" puede servir para la recuperación y el despliegue de las fuerzas productivas del país y el funcionamiento de la economía. Es una válvula de escape.

Luego de quince años de férreo control de cambio, de infinidad de convenios cambiarios y de múltiples organismos de gestión (CADIVI, SITME, SICAD, SIMADI I, SIMADI II, DIPRO, DICOM, etc.) ahora el gobierno bolivariano «descubría» que la creciente dolarización informal del país era una "bendición". Y el «dólar criminal» pasó a ser un elemento positivo para la economía. 
La tremebunda escasez que todos pensaban que aumentaría, por la crisis o por las sanciones, ha disminuido considerablemente. Poco a poco se observa un importante crecimiento en la oferta de bienes y servicios. Muchos empresarios ven la oportunidad de emprender o rescatar viejos negocios que tenían mercados potenciales. La veloz carrera por posicionarse en ellos ha impulsado a muchos a arriesgarse con cierto éxito. El vigoroso incremento de «bodegones» repletos de mercancías importadas parece reflejar una demanda capaz de comprarlos usando dólares que por diversas vías entran a la economía: contrabando, minería ilegal, remesas, narcotráfico y lavado/corrupción.

\section{La dolarización esconde la destrucción del bolívar}

El júbilo de Maduro y de sus más cercanos colaboradores con la dolarización informal y desreglamentada no deja de ser asombroso. Los más connotados patriotas no se preocupan ahora por la pérdida de soberanía monetaria y de libertad económica que implica un proceso de dolarización. Parece que no se dan cuenta que la destrucción del bolívar no es sino la forma monetaria que toma la devastación económica. Hablamos de la ruina del poder adquisitivo, la precaria seguridad social, la desaparición de los ahorros y de los fondos que millones guardaban para su vejez. Evidentemente, la híperinflación como expresión de la pérdida total del valor de la moneda ha empobrecido a millones, destruido hogares y empujado a millones de personas a la emigración, que en el año 2020 muchos especialistas creen que podría aumentar fuertemente. Estaríamos hablando de casi un sexto de la población total los que ya pudieron haber emigrado en los últimos años.

La depreciación del bolívar con respecto al dólar compete al gobierno central que con mano de hierro dirige el BCV. El desastroso resultado de los indicadores no puede ser achacado a las sanciones de Trump ni al «bloqueo». Países como Cuba, Corea del Norte o Irán, fuertemente sancionados, no tienen ni el 0,5\% de la inflación que tiene Venezuela. Así que el caos monetario es una debacle cuya responsabilidad es enteramente interna.

Aterrizando en el tipo de cambio, no es difícil ver cómo el bolívar se ha depreciado en casi el $100 \%$, con respecto al dólar. En los dos últimos años (diciembre de 2017 a diciembre de 2019) el tipo de cambio ha aumentado un 4.140.709,75 \%. Si hacemos la medición desde diciembre de 2013 hasta diciembre de 2019 tendríamos que el tipo de cambio ha aumentado en $7.208 .437 .400,34 \%$. 
La voraz híperinflación que destruyó el bolívar (que es plenamente recuperable), impuso esta dolarización anárquica. Según casi todas las estimaciones, la cantidad de dólares es quizás unas ocho veces más grande que la cantidad de bolívares. La entrada de divisas por remesas, narcotráfico, corrupción (por las sanciones ya no se fugan tantas divisas), y contrabando de gasolina y minería ilegal, han hecho que frecuentemente se paguen hasta los más mínimos montos en dólares. Esta nueva realidad ha horadado la autoestima de muchas personas que devengan salarios de alrededor de 15 dólares mensuales, mucho más alto que el mínimo, y que ven como una pequeña parte de la sociedad compra carros de 150.000 dólares, caviar y oficinas de lujo.

Las clases que magistralmente bosquejó Karl Marx según sus atributos productivos, parecen reducirse en el imaginario venezolano en dos: los que ganan en divisas y los que reciben bolívares (los pobres). Florece la importación de lujo y la producción nacional desfallece. Un lumpencapitalismo se erige así entre la mar de ilegalidades, evasiones y bandas armadas extractivistas que se han hecho «empresarias» a fuerza de crímenes de todo tipo. El Estado se ausenta y se retrae. Los controles absurdos se abandonan de facto, pero con ellos las regulaciones necesarias también desaparecen. Reina el descontrol y se profundiza la desigualdad del ingreso en niveles nunca antes conocidos.

Aún así, hay alternativas a la debacle que se podrían comentar en otro artículo dedicado a ello en exclusiva. En ese sentido, en lo más inmediato, urge un programa de emergencia económica y social que se aleje de los intereses de los bandos políticos en disputa y coloque a la amplia clase trabajadora en la vanguardia. Partidos políticos pequeños, sindicatos, universidades y ONGs deben trabajar en la realización de un plan de emergencia que ordene y priorice sus honestas reivindicaciones. Ello organizaría su acción como requisito previo a las posibles alianzas que demandaría el impulso de un plan alternativo.

\section{La oposición más beligerante no quiere ir al diálogo y sueña con la intervención militar foránea}

La oposición más belicosa se empeña tozudamente en vender internacionalmente una debilidad del gobierno extrema. Aunque irriguen esas ideas desde el exilio y que no tengan ni partidos, ni sindicatos con fuerzas populares bajo su dirección, este segmento opositor de pujante esfuerzo mediático, se promociona a sí mismo como un ente poderoso, 
pero realmente no lo es. Aunque reciba ingentes cantidades de dinero de EEUU y sus aliados, ese apoyo no se refleja en ninguna estructura organizativa y no tiene el más absoluto arraigo de masas. Los intentos de golpes de Estado y sublevaciones son rápidamente repelidas por el gobierno. Con facilidad pasmosa frustran cada uno de sus planes que posteriormente son ridiculizados en prosaicas cadenas de radio y televisión. Esta ultra derecha entronca con el discurso anti-comunista más radical del orbe y vende la sibilina idea que muestra a Venezuela como el comunismo realizado. Tamaño disparate es mezclado con acusaciones que pechan al gobierno de narco, terrorista y otras cosas más. Como dice Francine Jácome, es evidente que el sostén del gobierno de Maduro han sido los militares, convertidos no solo en actores políticos sino también en empresarios que controlan los sectores más importantes de la economía. Por ello la insistencia de Guaidó y sus acólitos en tratar de resquebrajar a ese "poder tras bastidores" con ofertas de amnistía y estímulos, para que desconozcan al gobierno actual (JÁCOME, 2018).

Esta fracción de ultra derecha de la oposición expide la mayor radicalidad, en este caso, las muestras de odio de clase más fuerte. Aunque sus líderes de alguna forma se autolimitan, sus entusiastas acólitos en redes sociales, casi todos en el extranjero pero con más tiempo para dedicar a las redes, se encargan de aplastar con cobarde cyberbullying a todo aquel que difiere, así sea en centímetros, de esa forma de entender al gobierno. Con vomitivas agresiones aplastan a quienes desde el campo opositor plantean alternativas menos violentas que la invasión militar estadounidense, salida preferida por este grupo político, para encaminar un cambio político. Así las cosas, desde hace años este grupo se ha opuesto radicalmente al diálogo, y sólo aceptan una rendición incondicional de Maduro apenas tolerando que éste tome un avión con destino a Cuba, isla que según ellos domina colonialmente a Venezuela.

\section{Diálogo en Oslo, Estocolmo Y Barbados}

Fieles a su palabra, la ultra derecha que tutora a Guaidó y que sirve de correaje internacional con los halcones del partido republicano de EEUU, se alejó de toda iniciativa de diálogo, lo que para ellos demostraba su extraordinaria pureza política. Por todo ello los diálogos que llevan más de un año realizándose a sotto voce en Noruega no contaron con su ilustre participación. Los meses de enero y febrero de 2019, con sus éxitos momentáneos, 
parecieron darle la razón y los empujaron a radicalizarse en sus posturas, llevándose con ellos a Guaidó, que con su mediático mantra "Cese de la usurpación, gobierno de transición y elecciones libres", parecía condenar al ostracismo al candoroso diálogo, una -según ellostrampa malévola de la "narcodictadura" para ganar tiempo. A cada instante aseguraban que: "con delincuentes no se negocia".

La euforia de inicios del año ha pasado a una situación de estancamiento que muchos opinadores antichavistas llaman "empate catastrófico", tratando de hacer pasar sus deseos, como la realidad objetiva. Intentan de algún modo colocar la idea de una cierta equivalencia de fuerzas políticas entre ambos bandos, poderío que honestamente no vemos en una oposición atomizada y famélica. Peor aún, tratan de vender la situación actual del gobierno como si tuviese una especie de soga al cuello, porque la feroz crisis económica "continúa" y porque EEUU le arrebató varios activos en el extranjero al país. Semejante espejismo se ve constantemente contrastado con el inexistente poder real que detenta la Asamblea Nacional (AN), cuyos obreros ni cobrar sus salarios pueden. Ni hablar de la pasmosa sencillez con que el gobierno los reprime, encarcela y desbarata los planes de derrocamiento más avezados.

En esta puesta de escena, a regañadientes, Guaidó ha tenido que reconocer que Stalin González, protagonista muy cercano a su presidencia de la AN, era miembro activo del proceso de diálogo, lo cual quiere decir que estaba participando en las negociaciones. Ello enervó a la ultra derecha, pero no pudo hacer más que escribir algunos tweets. En aquel beatus ille del lejano febrero de 2019, condenaron la idea con denuedo, pero ahora ya parecen resignados a un proceso de negociación donde van a exigir cosas muy por arriba de sus fuerzas reales, muy debilitadas ya por meses de dislates, riñas estériles y una vocación a la aventura política chocarrera. En estas condiciones el diálogo no era para ellos un éxito, como lo debería ser para toda oposición en semejantes condiciones, no era más que una actividad vergonzante, una humillación que realizaban a hurtadillas.

El empecinamiento presuntuoso en denostar de la negociación y en llamar "blandengues" y colaboracionistas a los opositores que la apoyan, deja a la muy debilitada oposición, en el hic et nuc de finales de 2019, con escasas opciones, ya que la sanguinaria salida de la invasión, ha sido constantemente descartada por el alfil de Trump para el caso venezolano, Elliott Abrams, quien no sólo ha dicho que los marines no entrarían al país ni habría bombardeos, sino que la ruta es democrática y que ella incluye al chavismo como actor 
fundamental. Incluso ha afirmado que el chavismo debe regresar a la $A N$, lo que efectivamente ocurrió meses más tarde, y que entre todos deben construir una transición pacífica.

En los hechos concretos la oposición no tiene nada con que forzar a su enemigo a la rendición, nada. No tiene como amenazarle y no cuenta con ningún impulso popular sólido y organizado para ejercer presión política interna. Las sanciones serían lo único que al gobierno le pudiera interesar y sería bastante poco para hacerlo cambiar en su aspiración de eternamente permanecer en el poder y concentrarlo de manera monárquica absolutista. El asunto clave de ello es que las sanciones las impone EEUU y la negociación más directa sería entre los secuaces de Trump y de Maduro, donde la oposición sería algo menos que un adorno. Detrás de Maduro está China, Rusia y Turquía, por lo cual la negociación sería un poco más arriba de lo aparente.

Ante ese infausto panorama, la oposición naufraga en un ser o no ser más propio del olvido, que de un dilemático Hamlet. Ofrece la oportunidad de una salida rápida del gobierno, pero no tiene fuerzas para hacerlo. Cree en quimeras y en milagrosas huidas gubernamentales. Aspira a que el gobierno reflexione sobre la atroz crisis económica que ha creado, y luego de alguna epifanía: que renuncie con gallardía. Sueña a su vez con una invasión liberadora que aniquile a la dirección del chavismo en una operación quirúrgica, pero ni aún así tendría capacidad de tomar el poder en un país que estaría hecho un polvorín. Observa los movimientos de apertura e intentos de cambio en el seno del chavismo, e inmediatamente los condena y agrede. Mira la llegada de un diálogo en el cual sin tener nada podría sacar petróleo, y simplemente lo desdeña en pro de unas fantasías donde se imagina a sí misma como el Titán que no es, ni será por un tiempo.

\section{EEUU, Trump y alternativas factibles en el diálogo: luz en las sombras}

En lo que respecta a Venezuela, el gobierno de Trump juega también al consabido: policía bueno y policía malo. De cuando en vez, Eliott Abrams sale hablando de la necesidad de una transición de la mano del chavismo y respetando sus derechos. Casi al mismo tiempo, Pompeo aparece hablando de la necesidad imperiosa de condenar al chavismo al más duro de los ostracismos, particularmente a Maduro y a sus allegados. A pesar de ese juego que en voz de Marx sería una manifestación grosera de falsa conciencia con intenciones de 
manipulación política, el gobierno de EEUU sigue tratando de obtener una victoria expedita en el caso venezolano. La víspera de las elecciones presidenciales en EEUU presiona para que Trump acelere una posible victoria con la cual pueda ufanarse ante el Lobby ultra derechista de latinos en Florida. Ello es más importante ahora, dada las políticas de extradición y persecución a los inmigrantes, que protagoniza su gobierno, en una suerte de repulsivos pogromos. Es de recordar lo valioso para la negociación que resultan las sanciones personales y económicas que EEUU puede revertir en el mismo instante en que alguien se apegue a su interés más inmediato.

Voces (optimistas) que dimanan de la mesa de diálogo, sugieren que Maduro está mucho más dispuesto a la negociación de lo que parece. Según este sector, el Presidente del Ejecutivo estaría dispuesto a ir a elecciones presidenciales con un nuevo Consejo Nacional Electoral (CNE). Por más extraño que parezca, estas personas han comentado que Maduro exige la renuncia de Guaidó, para no enfrentarse en una reyerta electoral directamente contra él. Aunque la popularidad de Guaidó ha disminuido en la medida que la promesa de una salida fulminante del gobierno se alarga indefinidamente en el tiempo, parece según todas las encuestas ser el "único" líder de la oposición que ronda el 40\% de aprobación en los sondeos de opinión. Casi todos los líderes opositores han sido condenados al destierro o se han ido desgastando por las derrotas electorales (Henrique Capriles). Leopoldo López, mentor de Guaidó, lleva muchos años preso y lejos de la movida política pública. Ahora, está refugiado en la embajada de España sin hacer acción política de calle. Guaidó constantemente está en campaña, marcha por pueblos y ciudades asiduamente. Abraza a las abuelitas y carga a los niños en los barrios y luego asciende a una tarima a hacer la mar de promesas que sólo alguien en el estruendo del desespero y la angustia puede creer; pero en la dramática crisis nacional es el único quien de alguna manera les brinda alguna esperanza de cambio.

La cúpula partidista de la oposición en general no quiere mucho a Guaidó. Salvo algunos casos particulares de socios adheridos a última hora, la élite de los partidos no acompaña a Guaidó en prácticamente ninguno de sus eventos, salvo muy contadas excepciones. La sectaria vocación de poder de Voluntad Popular (VP), sus ansias de no compartir los espacios, ni las munificentes ayudas internacionales crematísticas para la "lucha por la libertad", le han granjeado desde hace años una fuerte separación con los demás 
partidos. Dicho sentimiento es mutuo. VP se considera a sí mismo como un partido mártir. En sus adentros considera que ha puesto a centenares de presos, desterrados y fallecidos en las luchas callejeras violentas contra el gobierno. Cree que el resto de la oposición los ha dejado solos varias veces y que a pesar de ser el cuarto partido en tamaño, de una oposición extremadamente pequeña, ellos merecen en solitario tener el poder y aplicar su programa de forma unívoca.

A pesar de las fuertes resistencias soterradas de partidos más grandes que VP, como Acción Democrática y Primero Justicia, es de cuasi conocimiento público que Guaidó ganaría unas primarias de hacerse en tiempo breve. Incluso, algún sondeo inicial podría aclamar a Guaidó como candidato de consenso sin ir a primarias, a pesar de la marcada animadversión que levanta su partido en amplios sectores, y del desgaste político que implica el fracaso de su mantra y la lentitud de su posible aplicación parcial luego de una mesa de diálogo de la cual él mismo renegó varias veces. Por todo ello hay un sector grande de la oposición a quien le gustaría llevar el diálogo lo más pausadamente posible. Ello podría erosionar más aún la popularidad de Guaidó y aminorar la fuerza que levanta la campaña electoral permanente que realiza a diario. Con el pasar del tiempo eso se carcomería el impulso y el auge de Guaidó, con lo cual estos partidos pudieran reorganizarse mejor y plantear una alternativa sólida para unas elecciones internas, donde tuvieran cierta oportunidad. Los acólitos de Guaidó vieron ello y trataron por todas las vías de apresurar la negociación, hasta que ésta se rompió. Evidentemente el gobierno va por la vía opuesta.

En resumidas cuentas, el diálogo es sólo la punta de un iceberg político trascendental que transita con vertiginosa prisa. Fruto del diálogo se ha logrado de alguna manera empezar a reestructurar al CNE e incluir a dos rectores pertenecientes a partidos de oposición que fueron minoría en las elecciones parlamentarias de 2015. Así las cosas, a finales del año 2020 se prevé otra elección donde el grueso de los partidos opositores al régimen, digamos, los que más curules obtuvieron en 2015, no van a participar, por ello se prevé una fuerte abstención y un desconocimiento frontal de esa elección, a falta de 6 meses para celebrarla. La "fiesta electoral" ha secuestrado el tema de mayor centralidad en la actualidad, un acuerdo humanitario parar frenar la crisis actual. Acuerdo que luce muy lejos ahora, pero que parece prioritario por la extrema gravedad de la crisis actual, que ha sido severamente impulsada por el drama de la pandemia y el confinamiento. 
Amanecerá y veremos.

\section{Referencias}

BCV, B. C. Indicadores. [S.I.], 21 mayo 2014. Disponible en:

http://www.bcv.org.ve/c2/indicadores.asp.

BCV. Banco Central de Venezuela. [S.I], 23 feb. 2016. Diponible en: www.bcv.org.ve

BCV. Banco central de Venezuela. [S.I.], 15 oct. 2016. Disponible en: www.bcv.gov.ve

BCV. Banco Central de Venezuela. [S.I.], 1 de may. 2018. Disponible en: http://www.bcv.org.ve/

BRABOFF, C. Problemas reales para la negociación. Viento Sur, [s.I.], 22 may. 2019.Disponible en: https://vientosur.info/spip.php?article14831.

EN: La economía venezolana contrajo 50\% desde 2013. El Nacional, Caracas, 12 sep. 2018. Disponible: http://www.el-nacional.com/noticias/politica/economia-venezolana-contrajo-desde2013_251552.

CALLAMA, Barbara. Asamblea Nacional: Inflación de 2018 cerró en 1.698.488\%. Diario El Universal, Caracas, 9 ene. 2019. Disponible en: http://www.eluniversal.com/economia/30108/la-inflacion-dediciembre-fue-1418-abriendo-2019-en-1698488.

GARCÍA BRITO, C. En Venezuela, la reforma agraria es un objetivo común para las bases y el gobierno. Diálogos, propuestas, historias para una Ciudadanía Mundial. [S.I.], 1 ago. 2004. Disponible en: http://base.d-p-h.info/es/fiches/dph/fiche-dph-6985.html.

GARRIDO, L. J. El camino es el socialismo, dijo Hugo Chávez en Porto Alegre. La Jornada, Benito Juárez, 31 ene. 2005. Disponible en: http://www.jornada.unam.mx/2005/01/31/048f1con.php.

INSTITUTO NACIONAL DE ESTADÍSTICAS (INE). Sociales: Fuerza de trabajo. Caracas-Venezuela, 18 feb. 2017. Disponible en:

http://www.ine.gov.ve/index.php?option=com_content \&view=category\&id=103\&ltemid=40

JÁCOME, F. Los militares en la política y la economía de Venezuela. Nueva Sociedad, Buenos Aires, Argentina, n. 274, mar./abr. 2018. Disponible en: https://nuso.org/articulo/los-militares-en-lapolitica-y-la-economia-de-venezuela/.

KORNBLIHTT, J. El creciente peso del Estado en el comercio exterior venezolano como expresión de la contracción de la renta petrolera y la agudización de la disputa por la misma. CEICS. Aún sin Publicar de 2015.

KORNBLIHTT, J. Análisis de la renta en Venezuela. Buenos Aires, Argentina, 10 mar. 2016.

MARTíN, S. El diálogo en Noruega no es buen augurio para Venezuela. Panam Post, [s.I.], 16 may. 2019. Disponible en: https://es.panampost.com/sabrina-martin/2019/05/16/dialogo-en-noruegavenezuela/.

MOMMER, B. La cuestión Petrolera. Caracas: Ediplus, 1998. 
MOMMER, B. Petróleo Global y Estado Nacional. Caracas: Comala, 2003.

MUR, R. Chavismo y oposición venezolanos reanudan el diálogo en Barbados. La Vanguardia, [s.l.], 16 jul. 2019. Disponible en:

https://www.lavanguardia.com/internacional/20190715/463495785778/chavismo-opisicion-

venezolanos-reanudan-dialogo-barbados.html.

RONDÓN, C. M. País de estreno, 37 entrevistas antes de que el país nos alcance. Caracas: El Nacional, 1998.

SALAS, J. B. PIB se desplomó totalmente en el 2016. Ecoanalitica, [s.I.], 14 mar. 2017. Disponible en: https://www.elimpulso.com/2017/03/14/pib-se-desplomo-totalmente-2016/.

SANTAMARÍA, F. Noruega quiere entender crisis venezolana sin discursos ideológicos. El Estímulo, [s.l.], 15 mayo 2019. Disponible en: https://elestimulo.com/crece-interes-en-norvega-por-entendercrisis-venezolana-sin-discursos-ideologicos/.

SUTHERLAND, M. Crítica a la política económica del "socialismo del siglo XXI": apropiación privada de la renta petrolera, política de importaciones y fuga de capitales. Estudios Latinoamericanos, [s.l.], n. 38, p. 39-63, dec., 2016.

SUTHERLAND, M. El desastre monetario en Venezuela, billetes de Bs. 100, inflación y una alternativa. Alemcifo, [s.I.], 22 feb. 2017. Disponible en:

https://alemcifo.wordpress.com/2017/02/22/el-desastre-monetario-en-venezuela-billetes-de-bs100-inflacion-y-una-alternatival.

SUTHERLAND, M. La ruina del Socialismo no se debe al "socialismo" ni a la "revolución". Nueva Sociedad, Buenos Aires, Argentina, n. 274, p. 142-152, abr. 2018.

SUTHERLAND, M. Investigación especial impacto y naturaleza real de las sanciones económicas impuestas a Venezuela. PROVEA - Programa Venezolano de Educación Acción en Derechos Humanos. [S.I., 27 may. 2019.Disponible en:

https://provea.org/publicaciones/investigaciones/investigacion-especial-impacto-y-naturaleza-realde-las-sanciones-economicas-impuestas-a-venezuela/.

SUTHERLAND, M. Maduro... Nueva Sociedad, Buenos Aires, mayo 2020. Dispoible en: https://www.nuso.org/articulo/maduro-Guaido-Venezu.

\section{Author details}

Manuel Sutherland

Universidad Central de Venezuela (CENDES) Ciudad Universitaria de Caracas, Venezuela. Es Economista Doctorando en Estudios del Desarrollo del CENDES, y es director del Centro de Investigación y Formación Obrera (CIFO), Caracas, Venezuela. E-mail: alemcifo@gmail.com 